\title{
Pro-Nucleotides - Recent Advances in the Design of Efficient Tools for the Delivery of Biologically Active Nucleoside Monophosphates
}

C. Meier*

Institut für Organische Chemie, Julius-Maximilians-Universität Würzburg, Am Hubland, 97074 Würzburg, Germany

Tel. +49-931-8885326; Fax +49-931-8884606; e-mail: meier@chemie.uni-wuerzburg.de

Received 10 September 1997

Dedicated to Professor Gernot Boche on the occasion of his 60th birthday

\begin{abstract}
A summary of the most recent advances to the design of pronucleotides will be presented. Approaches that have been designed to be activated by enzymes such as carboxyesterases [bis(POM)-, bis(POC)-, bis(SATE)-, bis(AB) phosphotriesters and the arylphosphoramidates] or by reductases [bis(SDTE) approach] will be discussed as well as the amino acids phosphoramidate diester concept with its still unknown delivery mechanism and the cycloSal approach that releases the nucleotides by an induced tandem reaction.
\end{abstract}

Nucleoside analogues, e.g. 2',3'-dideoxy-2',3'-didehydrothymidine 1 (d4T), 3'-azido-2',3'-dideoxythymidine 2 (AZT) or 5-fluoro-2'deoxyuridine 3 (5-FdU), are structurally different as compared to the corresponding natural DNA or RNA nucleosides with regard to modification of the glycon as well as the aglycon residue. Due to this modified structure, these compounds are widely used as antiviral or antitumor drugs in chemotherapy (Figure 1$)^{(1)}$. Since the discovery of AZT 2 as the first nucleoside drug for the treatment of AIDS, considerable efforts have been made to develop new nucleoside analogues that would be more active, less toxic inhibitors of the HIV-1 reverse transcriptase $(\mathrm{RT})^{(2)}$. The general mode of action of nucleoside analogues is the inhibition of the HIV-1 RT by acting as competitive inhibitors or as DNA chain terminators. To act as DNA chain termination agents or RT inhibitors, intracellular conversion of the nucleoside analogues into their 5'-mono-, 5'-di- or 5'-triphosphates is a prerequisite after cell penetration ${ }^{(3)}$. The enormous disparity in antiHIV activity that is evident for a large number of dideoxynucleoside analogues belies their apparent structural similarity. Due to these structural differences as compared to natural nucleosides the metabolization to the corresponding dideoxynucleoside triphosphates is often inefficient and consequently the therapeutic efficacy is sometimes limited $^{(4)}$. For example, in the case of the anti-HIV active dideoxynucleoside analogue d4T 1 (Stavudine, Zerit $\left.{ }^{\circledR}\right)^{(5)}$ the first phosphorylation to d4T 5'-monophosphate 4 catalyzed by thymidine kinase (TK) is the rate-limiting step in human cells ${ }^{(6)}$. More striking, however is $2^{\prime}, 3^{\prime}$-dideoxyuridine triphosphate (ddUTP) which is one of the most powerful and selective inhibitors of HIV reverse transcriptase $\left(\mathrm{K}_{\mathrm{i}}=0.05 \mu \mathrm{M}\right)$ while the parent nucleoside 2',3'-dideoxyuridine $\mathbf{5}$ (ddU) is virtually ineffective at blocking HIV infection in cultured cells. Biochemical and pharmacological studies in three different human $\mathrm{T}$ cell lines (CEM, ATH8 and Molt-4) showed that ddU 5 itself was not anabolized to the 5 '-monophosphate, most apparently because it was a poor substrate for cellular nucleoside kinases because of the considerable substrate specificity of these enzymes ${ }^{(7)}$. In contrast, in a few cases the limited efficacy is also due to a catabolic enzymatic reaction. For example, 2',3'-dideoxyadenosine $\mathbf{6}(\mathrm{ddA})$ is rapidly intracellularly deaminated to ddI 7 by adenosine deaminase (ADA) ${ }^{(8,9)}$. As a consequence, ddI 7 has to be converted into its ultimate bioactive metabolite ddATP via ddAMP 8 by five enzymatic steps (5'nucleotidase, adenylosuccinate synthase, adenylosuccinate lyase and two nucleotide kinases $)^{(8,9)}$. Finally, the resistance of the human immunodeficiency virus to the clinically used antiviral dideoxynucleoside AZT 2 (Zidovudine, Retrovir $\left.{ }^{\circledR}\right)^{(10)}$ is on the one hand directly related to multiple point mutations within the HIV-1 reverse transcriptase gene of the virus but may on the other hand be also due to lower susceptibility of resistant target cells to the drug related with a decreased activity or inability of the enzyme thymidine kinase to phosphorylate AZT 2 to the dideoxynucleoside monophosphate AZTMP $\mathbf{9}^{(11)}$.<smiles>Cc1cn(-c2ccc(O[W])cc2)c(=O)[nH]c1=O</smiles>

1: $Y=H(d 4 T)$

4: $Y=P(O) O_{2}^{2-}(d 4 T M P)$

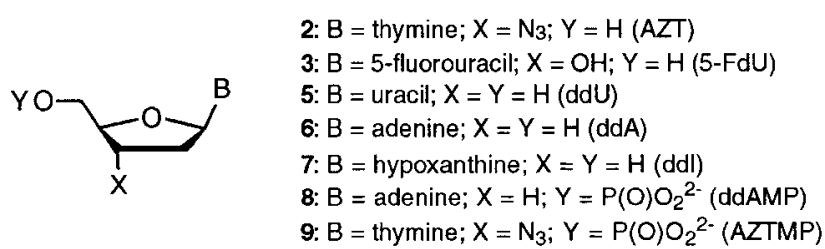

Figure 1. Examples of nucleosides and nucleotides used as antiviral and antitumor drugs

Consequently, direct administration of the nucleotides d4TMP 4, ddAMP 8 and AZTMP 9 should bypass these limiting steps and hence has advantages for the biological activity. Unfortunately, because of the high polarity of the nucleoside monophosphates (nucleotides), these compounds are not able to easily penetrate cellular membranes or the blood-brain barrier. However, the phosphate moiety offers a suitable site to attach degradable lipophilic carrier residues. As a result, one effort to improve the therapeutic potential of nucleoside analogues is the delivery of the corresponding nucleotide from neutral, membranepermeable prodrugs (Pro-Nucleotide Approach; Figure 2) ${ }^{(12)}$.

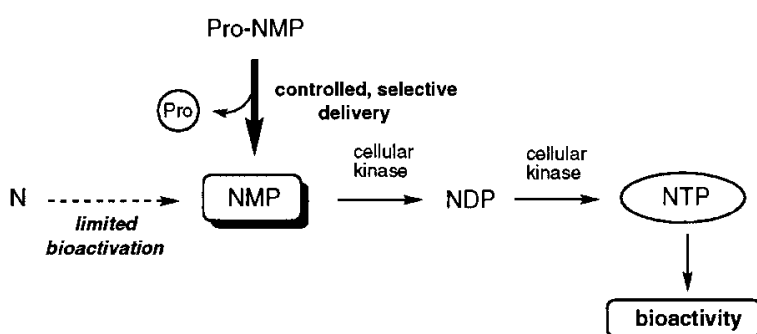

N: Dideoxynucleoside analogue

Figure 2. General principle of the pro-nucleotide approach of biologically active dideoxynucleotide analogues 
So, a lipophilic phosphotriester may penetrate into the target cell where first partial and at the end complete hydrolysis delivers the nucleotide.

A suitable nucleotide prodrug has to fulfill two requirements: i) it has to be lipophilic enough for passive diffusion of the membrane and bloodbrain barrier; ii) furthermore, it should be able to deliver the nucleoside hydrolytically or enzymatically leaving a non-toxic masking group ${ }^{(13)}$.

In principle, two different concepts for prodrug design are known: bipartate and tripartate prodrugs. In the former concept the drug is modified by a one-component masking group. In this form the drug is biologically inactive. After a simple cleavage of the mask, the active drug is liberated (Figure 3). In the latter concept, the drug is modified by a two-component masking group. Again, the drug is biologically inactive in this bound form. The mechanism of liberation involves a first chemical or enzymatic reaction under cleavage of part I of the masking moiety. The drug is still inactive but the effect of this first reaction is an activation of the remaining masking group II with the consequence of a spontaneous successive cleaving reaction releasing the now bioactive drug (Figure 3) ${ }^{(14)}$

\section{The bipartate prodrug concept}

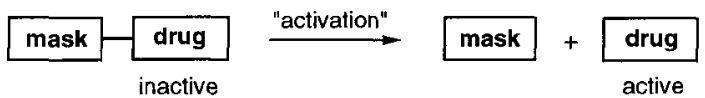

The tripartate prodrug concept

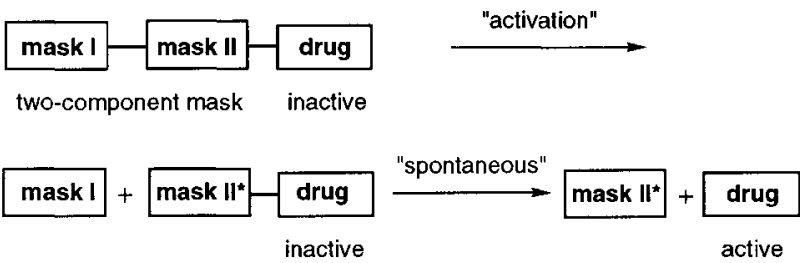

Figure 3. General principle of prodrugs bearing one-component or two-component masking groups

In the case of a nucleotide prodrug one should take into account that under physiological conditions two negatively charged phosphate oxygen's have to be masked in order to obtain a neutral, lipophilic phosphate ester. Consequently, not only one masking group is necessary but two. So, the efficient intracellular delivery of nucleotides from a prodrug requires the existence of a specific delivery mechanism or different rates of conversion of the prodrug to the drug intracellularly versus extracellularly. One comment with respect to toxic side events should be given. Neutral phosphorus derivatives with a good leaving group attached to the phosphorus are known to be toxic suicide inhibitors of acetylcholinesterase ${ }^{(15)}$. The anti-acetylcholinesterase activity of phosphorus derivatives is an inverse function of the $\mathrm{pK}_{\mathrm{a}}$ of the leaving group on the phosphorus atom and parallels the rate of spontaneous hydrolysis by $\mathrm{P}-\mathrm{O}$ bond cleavage ${ }^{(16)}$. In order to circumvent the possible problem of anti-cholinesterase activity, neutral phosphate ester prodrugs should be designed to undergo heterolytic cleavage of the $\mathrm{C}-\mathrm{O}$ bond rather than the $\mathrm{P}-\mathrm{O}$ bond of the ester.

Many strategies have been developed to achieve this goal. As a general motive, uncharged nucleotide triesters are used as membrane-permeable nucleotide precursors ${ }^{(12)}$. The major differences of these approaches are the delivery mechanisms to the nucleotides. First attempts have been made with simple dialkyl phosphotriesters. These compounds generally belong to the class of bipartate prodrug systems. After a first, sometimes selective hydrolysis of the phosphotriester via a nucleophilic reaction at the phosphorus center, the resulting phosphodiester is often extremely stable against a further chemical hydrolysis due to the charge at the phosphate which prevents a second nucleophilic reaction ${ }^{(17)}$. Even if the subsequent hydrolysis is possible, one should take the pseudorotation phenomenon into account that excludes a selective delivery of the nucleotide ${ }^{(18)}$. As a consequence, almost all approaches based on chemical hydrolysis reported so far were unable to deliver the nucleotide selectively except the cycloSal approach that will be discussed later. For this reason, the newer pro-nucleotide approaches are based on the concept of a tripartate prodrug system ${ }^{(14)}$ and are based on the general idea of a selective chemical or enzymatic reaction within the masking group which leads to a second, spontaneous successive reaction yielding the charged phosphate ester. These approaches utilize and exploit the differences in reducing potentials, enzyme activity, and $\mathrm{pH}$ value. The concepts working with enzymatic trigger processes (bis(POM)-, bis(POC)-, bis(DTE)-, bis(SATE)-, bis(AB)- and the arylphosphoramidate concept) as well as the cycloSal approach based on a pH-driven degradation have demonstrated the successful intracellular delivery of free nucleotides from lipophilic precursors.

It should be added, that it is not the intention of the author to give an entire overview of the pro-nucleotide field. The current review highlights some approaches that have been designed to deliver the nucleotide selectively by a special mechanism. With this selection, the author wants to point out that designing a delivery mechanism and bypassing a certain limiting metabolization the inherent biological potential of an already known nucleoside analogue could be used to a higher extent and consequently, the improvement in antiviral activity could be, in many cases, better than synthesizing new potential nucleoside analogues. Furthermore, this review is restricted to the delivery mechanism and so the synthesis of the compounds may be gleaned from the original literature.

Biographical Sketch

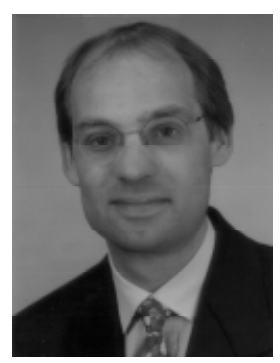

Chris Meier, born 1962 in Berlin, was trained in Chemistry at the University of Marburg. He passed his Diploma and Ph.D. thesis in the group of Prof. G. Boche in Organic Chemistry. Then he moved as postdoc fellow to the Pasteur-Institute in Paris where he started his work in nucleoside and oligonucleotide chemistry. In 1991 he joined the group of Prof. J.W. Engels at the University of Frankfurt/Main starting his Habilitation which he finished in July '96 and in May '97 he was appointed as an associate professor at the University of Würzburg. 


\section{Bis(POM)- and Bis(POC)-Nucleotides}

The first approach reported by D. Farquhar et al. towards a new class of tripartate pro-nucleotides are the bis(pivaloyloxymethyl)- [POM] phosphotriesters of general type $\mathbf{1 0}$ (shown exemplified as the ddU derivative $)^{(19,20)}$. This approach utilizes a carboxyesterase-catalyzed cleavage of the pivaloyl ester within the POM-masking group to yield the highly reactive hydroxymethyl phosphotriester $\mathbf{1 1}$ which subsequently eliminates spontaneously formaldehyde to give the mono(POM) phosphodiester 12. The carboxyesterase which is used for this activation process may be more prevalent inside the cells. To obtain the free nucleotide, this enzymatic activation has to be repeated via $\mathbf{1 3}$ or, alternatively, a phosphodiesterase cleaves the phosphodiester $\mathbf{1 2}$ directly to yield the nucleotide (Figure 4).

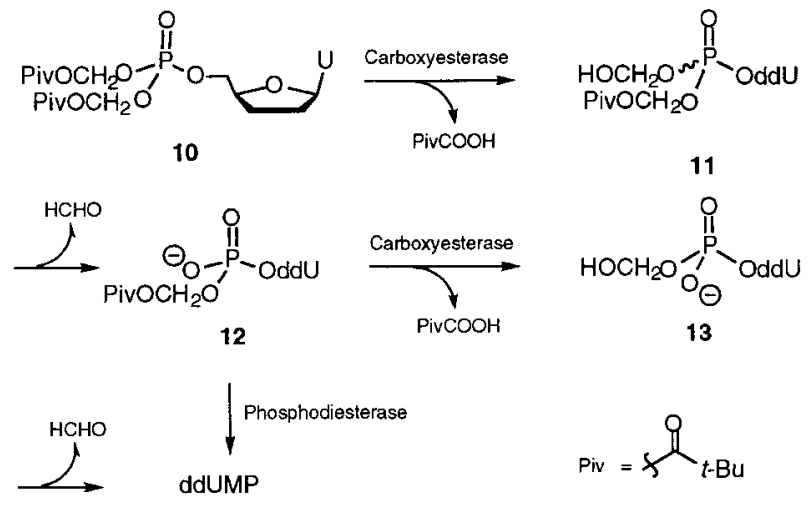

Figure 4. Bis(POM)-nucleotides 10 shown here as their $2^{\prime}, 3^{\prime}$-dideoxyuridine derivatives and their degradation pathway

This approach has been applied successfully to the delivery of $2^{\prime}, 3^{\prime}-$ dideoxyuridine monophosphate from bis(POM)-ddUMP ${ }^{(21)}$. Furthermore, this concept has been used for the delivery of the anti-HIV drug $\operatorname{AZTMP}^{(22)}$, the anti-herpes and anti-HIV drug phosphonomethoxyethyladenine (PMEA) ${ }^{(23)}$ and for the antitumor active drug 5-fluoro-2'-deoxyuridine monophosphate (5-FdUMP) ${ }^{(24)}$. In the case of the phosphonate analogue PMEA a highly improved bioavailability was obtained. Moreover, the bis(POM) derivatives of $(R)$-9-(2-phosphonomethoxypropyl)adenine (PMPA) and (R)-9-(2phosphonomethoxypropyl)diaminopurine (PMPDAP) were found to be 9- to 23 -fold more active than the parental compounds ${ }^{(23)}$. However, the cytotoxicity of the bis(POM) analogues was also increased by virtually similar degrees. Nevertheless, studies with radiolabelled bis(POM)PMEA showed a considerable increase (100-fold) of the cellular uptake of PMEA by using the phosphonate diester ${ }^{(23)}$. In an independent study, ten different PMEA prodrugs tested in vivo for oral bioavailability in cynomolgus monkeys. From the results of this study, bis(POM)-PMEA was selected for human clinical trails. In these clinical trails, the oral bioavailability of bis(POM)-PMEA from a single $500 \mathrm{mg}$ dose was greater than $40 \%$ in fed subjects ${ }^{(25)}$. The in vitro antitumor tests of the bis(POM)-5-FdUMP triester demonstrated high growth inhibition in cell lines that were resistant to the usually used drug 5-fluorouracil. Furthermore, this triester derivative showed in vivo bioactivity after intraperitonal application against P 388 leukemia in mice. Beside the antitumor activity, these results verified also the penetration of the pronucleotide through cellular membranes ${ }^{(24)}$. A drawback of this approach is the requirement of a second identical activation reaction because the intermediate phosphodiester is a significantly poorer substrate for the activating carboxyesterases. Moreover, the delivery of one molecule of the nucleotides results in the liberation of two equivalents of potentially toxic formaldehyde and pivalinic acid (Figure 4). Additionally, it has been shown that the bis( $\mathrm{POM})$ phosphotriesters 10 were chemically unstable and highly susceptible to serum-mediated hydrolysis, factors which limit their potential utility for intracellular drug delivery ${ }^{(22,24 a)}$.

A modification of the bis(POM)-approach and a way to overcome the limitations observed with these compounds are bis(isopropyloxycarbonyloxymethyl)- [bis(POC)] nucleotides of general type 14 (shown as the PMPA derivative) that have been published very recently by A. Fridland et al. ${ }^{(26)}$ and L. Naesens et al. ${ }^{(27)}$. This modification uses a carbonate diester within the masking group. The mechanism of action is again a carboxyesterase-catalyzed cleavage of the isopropyl ester to give isopropanol and in the shown example the intermediate phosphonate diester $\mathbf{1 5}$ that fragmentates via 16 into carbon dioxide and formaldehyde and finally to the mono(POC) phosphonate ester 17. The mono(POC) ester $\mathbf{1 7}$ is subsequently degraded to yield PMPA or generally the nucleotide after a second carboxyesterase activation or by phosphodiesterase cleavage (Figure 5).

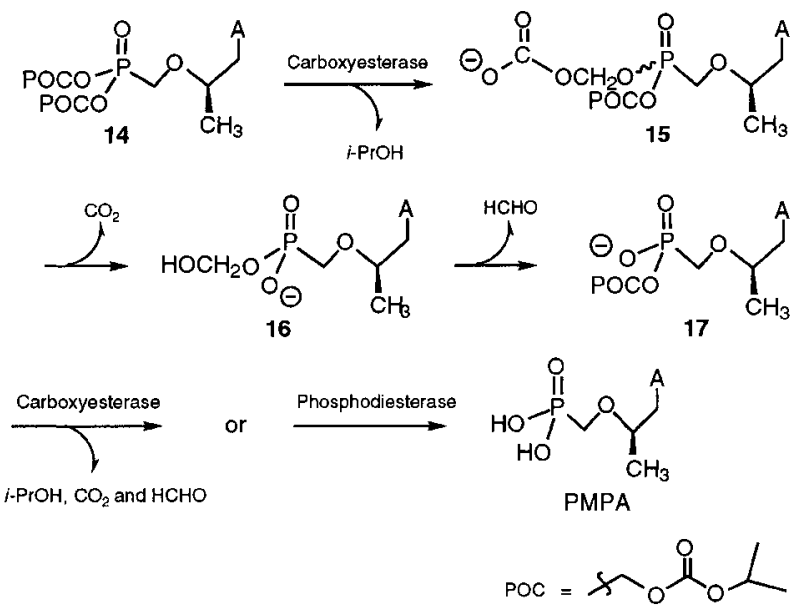

Figure 5. $\mathrm{Bis}(\mathrm{POC})$-nucleotides 14 and their esterase-catalyzed degradation pathway to yield ( $R$ )-9-(2-phosphonylmethoxypropyl)adenine as a representative drug

In contrast to the bis(POM)-approach, the bis(POC) modification avoids the formation of two equivalents of pivalinic acid that accumulate in the cells and potentially cause toxicity. The bis(POC)-approach was applied to the anti-HIV drug PMPA in order to increase the low bioavailability of this phosphonate derivative (Figure 5). Bis(POC)-PMPA is chemically stable at low $\mathrm{pH}$ and has shown $30 \%$ bioavailability in dogs with minimal toxicity in repeat 5 -day dosage of $60 \mathrm{mg} / \mathrm{kg} /$ day. The antiHIV activity of bis(POC)-PMPA 14 in human peripheral blood lymphocytes and in dentritic T-cell coculture system was 35- and 16fold, respectively, higher than that of PMPA. Bis(POC)-PMPA 14 was non-toxic at concentrations that completely suppressed viral replication. Studies of the metabolism of $\left[{ }^{3} \mathrm{H}\right]$-bis(POC)-PMPA showed that is was readily taken into the human cells, hydrolyzed to PMPA, and phosphorylated to the mono- and diphosphate derivatives. These results show that bis(POC)-PMPA 14 is a membrane-permeable form of PMPA and shows promise as a drug for the treatment of HIV infections ${ }^{(26)}$.

\section{Bis(SDTE)- and Bis(SATE)-Nucleotides}

Two further approaches that are also based on enzymatic activation have been reported by J.-L. Imbach and G. Gosselin ${ }^{(28)}$. They designed the bis(S-[2-hydroxyethylsulfidyl]-2-thioethyl)- [bis(SDTE)] 18 and the bis(S-acyl-2-thioethyl)- [bis(SATE)] nucleotides 19. The former concept was constructed to take advantage of the greater reducing potential within the cells to liberate the nucleotide into the cytosol. After 
the reductase cleavage of the disulfide bond in $\mathbf{1 8}$ with formation of thioethanol and thioethyl phosphotriester 20, this compound eliminates spontaneously episulfide to yield the intermediate phosphodiester 21. As in the case of the bis(POM)- (10) and the bis(POC) phosphotriester 14, the bis(SDTE) derivative 18 requires a second identical enzymecatalyzed activation step (Figure 6). The initial idea of this concept was, that the "soft" thiol-nucleophile in $\mathbf{2 0}$ will attack the "soft" electrophilic $\alpha$-carbon atom rather than the "hard" phosphorus atom in the elimination reaction avoiding possible pseudorotation processes ${ }^{(18)}$ because all reactions take place within the masking group without involving the phosphate ester moiety. This concept belongs also to the class of tripartate prodrugs. It could be shown that the bis(SDTE) triester of the nucleotides ddUMP and AZTMP 9 were cleaved 30-fold faster by reductases in cell extracts than in culture medium ${ }^{(28 c)}$. Furthermore, the bis(SDTE) approach has been applied to the nucleoside 5-FdU $3^{(29)}$ and to the phosphonate nucleotide PMEA ${ }^{(30)}$. Whereas an improvement in antiviral activity most probably due to an enhanced bioavailability for the bis(SDTE)-PMEA derivative 18 compared with PMEA was found, the bis(SDTE)-5-FdUMP failed to show better antitumor potency as compared to the free nucleoside ${ }^{(29)}$. The major limitation of this approach is the restricted chemically stability and high susceptibility to serum-mediated hydrolysis (Figure 6).

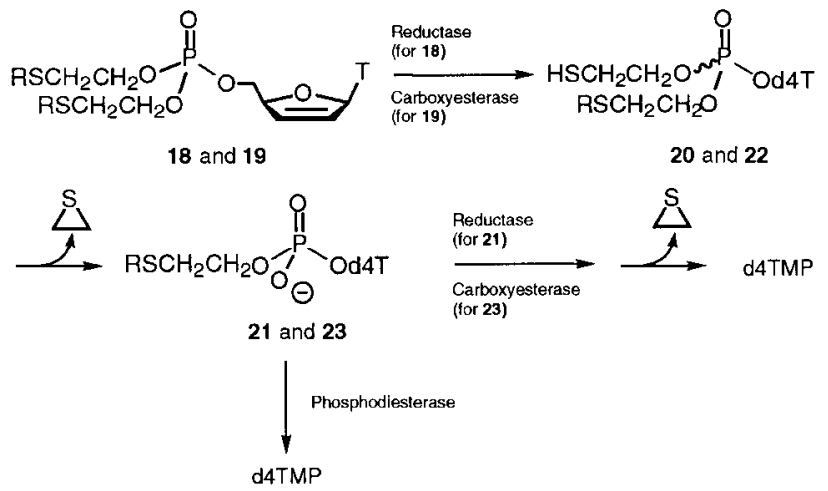

Bis(SDTE)-prodrug 18,20,21: $\mathrm{R}=\mathrm{SCH}_{2} \mathrm{CH}_{2} \mathrm{OH}$ Bis(t-Bu-SATE)-prodrug 19,22,23: $R=C(O)-t-B u$

Figure 6. Bis(SDTE)- and bis(SATE)-nucleotides 18 and $\mathbf{2 1}$ as their 2',3'-dideoxy-2',3'-didehydrothymidine monophosphate (d4TMP) derivatives and the enzymatic delivery mechanism

In contrast to the bis(SDTE) approach, the bis(SATE) approach is similar to the bis(POM) concept with respect to the activation process. Again, carboxyesterases are used to trigger the nucleotide delivery. Here, the enzyme cleaves a thioester in $\mathbf{1 9}$ to yield a carboxylic acid (as in the bis(POM) approach pivalinic acid) as well as the above mentioned thioethyl phosphonate diester 22 which undergoes a fragmentation to episulfide and the phosphonate monoester $\mathbf{2 3}$ (Figure 6). Thus, the spontaneous, second step is identical in the bis(SDTE) and the bis(SATE) concepts. Nevertheless, again two independent activation steps are required to yield the free nucleotide. With these two approaches, two equivalents of episulfide, which has been shown to be chronically and acutely toxic in mice and rats, are released besides the nucleotide ${ }^{(31)}$. The toxicity and moreover also mutagenicity has also been observed in vitro ${ }^{(32)}$. J.-L. Imbach and J.-P. Sommadoussi have shown that the introduction of the SDTE and the SATE group do not induce additional cytotoxicity of the phosphotriesters as compared to the parent nucleosides (e.g. AZT) in human myeloid colony-forming cells (human bone marrow cells) ${ }^{(33)}$. It should be mentioned that the stability of the bis(SATE) phosphotriesters could be adjusted by varying the thio ester residue: the lowest stability was obtained for thio esters of acetic acid whereas with increasing alkyl residue of the carboxylic acid the stability was increased. The optimized compounds are bis(SATE) compounds bearing two $S$-pivaloyl-2-thioethyl side chains as shown in Figure 6 because the highly lipophilic and sterically demanding $t$-butyl residue protects the masking group from too rapid cleavage as compared to the $S$-acetyl or $S$-i-propyl counterparts ${ }^{(28 d, 30 a, 31)}$. Again, J.-L. Imbach et al. demonstrated an increased stability of the bis(SATE) derivatives of AZTMP against degradation in culture medium as compared to cellular extracts ${ }^{(34)}$. The bis(SATE) approach has been successfully applied to the thymidine kinase-bypass (TK-bypass) of d4T $\mathbf{1}^{(35)}$ (shown in Figure 6) and AZT $\mathbf{2}^{(34)}$, the adenosine deaminase-bypass (ADA-bypass) of the anti-HIV active nucleoside ddA $6^{(36)}$ as well as for an improvement of the bioavailability of the anti-herpes and anti-HIV drug PMEA. Furthermore, the corresponding bis(SATE)-ddAMP triesters exhibited a higher stability than the dideoxynucleoside ddA 6 against acid-catalyzed depurination ${ }^{(36 a)}$. It should be mentioned that the bis(SATE)-AZTMP derivatives demonstrated a 10-fold decrease in activity from the wild-type $\mathrm{CEM} / \mathrm{O}$ cell line to the mutant $\mathrm{TK}^{-} \mathrm{CEM}$ cell line ${ }^{(34)}$. This result is puzzling but has also been observed by others. On the other hand, J. Cinatl, Jr. et al. ${ }^{(11 a)}$ have shown that the bis(SATE)AZTMP derivatives retained the biological activity of AZT 2 in AZT resistant Molt4/8 cells. Especially bis(S-pivaloyl-2-thioethyl)-AZTMP showed comparable cytotoxic and antiviral activity in sensitive and resistant cells. With these experiments, J. Cinatl et al. demonstrated that Molt $4 / 8^{\mathrm{r}} \mathrm{AZT}$ cells exert resistance to the anti-HIV activity of the drug mainly owing to the lack of AZT phosphorylation and that resistance may be bypassed by using AZT monophosphate prodrugs. However, as for the bis(POM) phosphotriesters $\mathbf{1 0}$ reported by D. Farquhar, the intermediate mono(SATE) phosphonate esters $\mathbf{2 1}$ and $\mathbf{2 3}$, respectively, are significantly lower substrates for the activating carboxyesterases due to the negative charge at the phosphonate residue in the vicinity of the enzyme cleavage site. Before hydrolysis takes place, the bis(SDTE) as well as the bis(SATE) phosphotriesters may serve as lipophilic precursors for a passive membrane permeation.

J.-L. Imbach et al. presented the comparison of the bis(SATE)-approach to the isomeric $S, S^{\prime}$-bis(O-acyl-2-oxyethyl) phosphorodithiolates ${ }^{(37)}$. Surprisingly, these derivatives proved as active as the original bis(SATE) triesters with the nucleosides d4T $\mathbf{1}$ and ddA $\mathbf{6}$, although the delivery mechanism could not be the same. Further work is in progress to study the cleavage mechanism. Recently, the same group extended their prodrug design to bis(S-glycopyranosyl-2-thioethyl) [bis(SGTE)] nucleoside phosphotriesters ${ }^{(38)}$. These compounds were designed to deliver the nucleotide by activation of glycosidases. However, no antiviral data have yet been published.

\section{Bis(AB)-Nucleotides}

One possibility to avoid the close vicinity of the negative charge of the intermediate phosphodiester and the enzyme cleavage site has been developed independently by S. Freeman et al. ${ }^{(39)}$ and A. Glazier ${ }^{(40)}$. The common motive of their approaches is to separate the phosphate group and the carboxyesterase cleaving site by a rigid spacer. Consequently, they are using bis(4'-acyloxybenzyl)- [bis(AB)] nucleotides $\mathbf{2 4}$ and $\mathbf{2 5}$, respectively (shown as their AZTMP derivatives) instead of the $O$-acyloxymethyl or the $S$-acyl-2-thioethyl residue, respectively. As Freeman calculated a separation of about $4 \AA$, which she states is enough to avoid electrostatic disturbance of the anionic phosphate and the carboxyester residue ${ }^{(41)}$. The degradation mechanism of the bis( $\mathrm{AB})$ nucleotides of type $\mathbf{2 4}$ is the following: the enzyme cleaves the ester moiety in the 4'-position of the aromatic ring to give 
the 4'-hydroxybenzyl phosphotriester 26. Again, a subsequent spontaneous fragmentation of $\mathbf{2 6}$ is induced by this enzymatic reaction resulting in the formation of phosphodiester 27 and the 4'hydroxybenzyl cation $\mathbf{2 8}$ which is oxidized to yield the 4'quinonemethide $\mathbf{2 9}$ or is quenched by water to yield 4'hydroxybenzylalcohol 30. Diester 27 could then be degraded after a second esterase activation or a phosphodiester cleavage to yield the nucleotide AZTMP 9 (Figure 7). The mechanism of delivery has been studied using methylphosphonate as model compound ${ }^{(42)}$. Obviously, these compounds are also tripartate prodrugs.
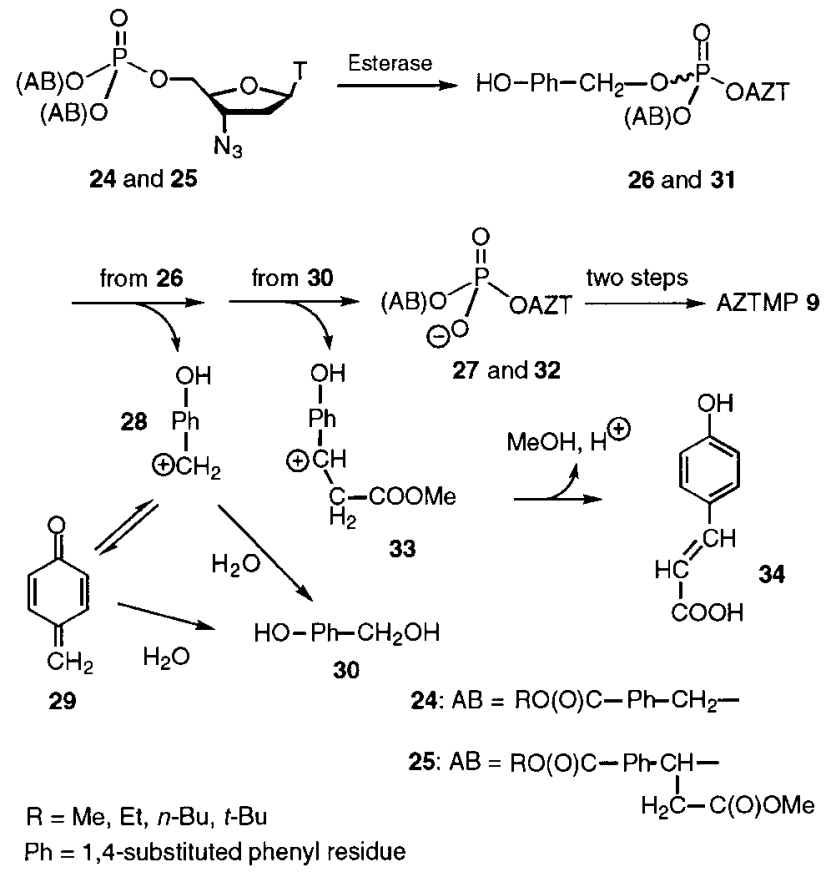

Figure 7. Delivery of $3^{\prime}$-azido-2', $3^{\prime}$-dideoxythymidine monophosphate (AZTMP 9) from bis(AB)-nucleotides 24 and 25

S. Freeman et al. applied their approach to the delivery of $\operatorname{AZTMP}^{(39,41)}$ and obtained in vitro antiviral activity against HIV-1 and SIV that was comparable to AZT 2. Unfortunately, she has not tested the compounds in thymidine kinase-deficient cells which could prove the direct intracellular delivery of AZTMP 9. Recently, S. Freeman applied their bis $(\mathrm{AB})$ approach to the intracellular delivery of foscarnet (PFA) from various precursors ${ }^{(43)}$. A possible limitation of the approach is the generation of the reactive benzylcation $\mathbf{2 8}$ in close vicinity of the active site of the enzyme because such cations are known to be potential alkylating agents that could react with side chains of amino acids ${ }^{(44)}$.

This possible problem was faced by the approach reported by A. Glazier using the bis $(\mathrm{AB})$ derivatives 25 (Figure 7$)^{(45)}$. Although the basic principle of the nucleotide delivery from $\mathbf{2 5}$ is essentially the same (carboxyesterase-mediated activation to give $\mathbf{3 2}$ via 31) as from triesters 24, the difference to the Freeman concept is the introduction of a methylmethoxycarbonyl group in the benzylic position of the $A B$ residue. The rationale for this substitution at the benzylic position is the possibility of a fast elimination reaction via the fleeting 4'quinonemethide $\mathbf{3 3}$ due to the electron-withdrawing methoxycarbonyl group that facilitates proton abstraction by decreasing the intrinsic barrier to proton removal. The transition state for proton removal is further stabilized by resonance delocalisation into the aromatic ring. The adjacent carbonyl group may also facilitate proton tautomerisation by acting by intramolecular general base catalysis. Firstly, this concept has been proven with $\operatorname{bis}(4$ '-acetoxy- $\alpha$-methylmethoxycarbonyl- benzyl)methylphosphonate. As expected, the final products after enzymatic deesterification were methylphosphonic acid, acetic acid and trans-4'-hydroxycinnamic acid 34. Without addition of esterase no detectable decomposition was noted. Secondly, Glazier demonstrated convincingly, that after two hours of incubation with porcine liver esterase a nucleoside phosphotriester bearing the anti-herpes drug acyclovir monophosphate (ACVMP) has nearly completely been converted to methanol, acetic acid, trans-4'-hydroxycinnamic acid $\mathbf{3 4}$ as well as ACVMP as sole reaction products ${ }^{(45)}$. This concept has been applied to the delivery of $\operatorname{AZTMP}^{(40)}$ and $\operatorname{ACVMP}^{(45)}$. However, a limitation of this approach may be the very short degradation half-lives of the compounds $\left(t_{1 / 2}=16 \mathrm{~min}\right)$. Furthermore, the bis $(\mathrm{AB})$ derivatives reported by A. Glazier et al. were highly lipophilic (log Pa value $=1.07$ to 4.18; depending on the carboxyacid ester residue) making systemic applications problematic ${ }^{(45)}$. Nevertheless, the bis(AB)-ACVMP derivatives showed promising in vivo activity against Herpes virus type1 infections without toxic side effects using concentrations up to 100 $\mathrm{mg} / \mathrm{kg}$ body weight ${ }^{(45)}$. Furthermore, no mutagenicity was found for the prodrugs in the Ames test with or without microsomal activation ${ }^{(45)}$. However, the compounds showed only a limited improvement in antiviral activity in vitro ${ }^{(45)}$. As acyclovir, the prodrugs showed no toxicity in vitro $\left(\mathrm{CD}_{50}>100 \mu \mathrm{M}\right)$. Moreover, bis( $\left.\mathrm{AB}\right)$ esters of PMEA were prepared and were found to be more potent in vitro than PMEA itself $^{(40)}$.

\section{Nucleoside Arylphosphoramidates}

Another novel class of a membrane-soluble enzyme triggered nucleotide delivery concepts are the phosphoramidate derivatives of type 35 recently reported by $\mathrm{C}$. McGuigan et al. ${ }^{(46)}$. The basic structure of these compounds (shown with the anti-HIV drug d4T 1) is depicted in Figure 8. In contrast to the previously mentioned phosphotriester approaches, in this case the structural motive involves a phosphate moiety that is linked to the nucleoside, a phenyl group and, through a phosphoramidate linkage, also to the methyl ester of $\alpha$-amino acid ester. This concept has been applied to the wide variety of nucleotides active against several viruses: d4TMP(47), AZTMP ${ }^{(48)}, 3^{\prime}$-thiacytidine monophosphate $(3 \mathrm{TCMP})^{(49)}$, $\operatorname{ddAMP}^{(50)}$ and 2',3'-dideoxy-2',3'didehydroadenosine monophosphate (d4AMP) ${ }^{(50,51)}$.

In in vitro antiviral tests, the $\mathrm{d} 4 \mathrm{~T}$ containing phosphoramidate was found to be slightly active as the parent nucleoside in wild-type CEM/O and MT- 4 cells. More importantly and in contrast to d4T 1, the d4TMP phosphoramidate completely retained the biological activity in mutant thymidine kinase-deficient CEM/TK ${ }^{-}$cells ${ }^{(47)}$ and suppresses HIV-1 infection in natural peripheral blood lymphocytes and freshly isolated monocyte/macrophages. This result proves that d4TMP 4 was delivered intracellularly making the observed activity of the compound almost entirely independent of thymidine kinase and consequently these compounds serve as efficient tools for the TK-bypass. The d4Tphosphoramidate was found to be equally active against HIV-1 and HIV-2 replication, and has also proved inhibitory to other retroviruses including simian immunodeficiency virus (SIV) and feline immunodeficiency virus (FIV), Visna virus and Moloney murine sarcoma virus in cell culture ${ }^{(52)}$. An interesting structure-activity relationship (SAR) has been found with these compounds: first, the presence of an $\alpha$-amino acid ester is essentially important for the biological activity. In contrast to $\alpha$-amino acid bearing compounds, simple alkyl amine derivatives exhibited a complete loss of antiviral activity ${ }^{(53)}$. The same was observed for derivatives bearing $\beta$-amino acid side groups. Among the natural $\alpha$-amino acids L-alanine was found to be the most effective ${ }^{(54)}$ while the enantiomeric D-alanine showed a 30 -fold decrease in bioactivity ${ }^{(55)}$. This interesting SAR points to an 
enzymatic action during the degradation of the phosphoramidates. The mechanism of degradation of the phosphoramidate of type $\mathbf{3 5}$ has been studied by J. Balzarini and C. McGuigan ${ }^{(56)}$ by the use of radiolabelled compound. Using this methodology, the intracellular levels of the 5'mono- (d4TMP), 5'-di- (d4TDP) and 5'-triphosphate (d4TTP) formed from the lipophilic precursor could be directly determined in wild-type $\mathrm{CEM} / \mathrm{O}$ and mutant CEM/TK ${ }^{-}$cells. Already in the wild-type cell line, the intracellular pools of d4TTP derived from the prodrug have been shown to be higher as compared to the d4TTP pools derived from the parent nucleoside $\mathrm{d} 4 \mathrm{~T}$ 1. Most striking, almost equal amounts of radiolabelled d4TTP have been detected in the wild-type and the thymidine kinase-deficient CEM cells for the d4T phosphoramidate while no detectable levels of d4TTP were found in CEM/TK ${ }^{-}$cells incubated with radiolabelled d4T 1. Again, this proves the efficient TKbypass caused by this phosphoramidate. Additionally, a novel metabolite has been detected in the cells and has been identified as alaninyl nucleotide 36. This metabolite exceeds the amounts of d4TTP by a 10 -fold (Figure 8 ). The main pathway by which alaninyl nucleotide 36 is formed either via the charged diester $\mathbf{3 7}$ or via esterase reaction on the carboxy ester leading to intermediate $\mathbf{3 8}$ has not yet clarified.

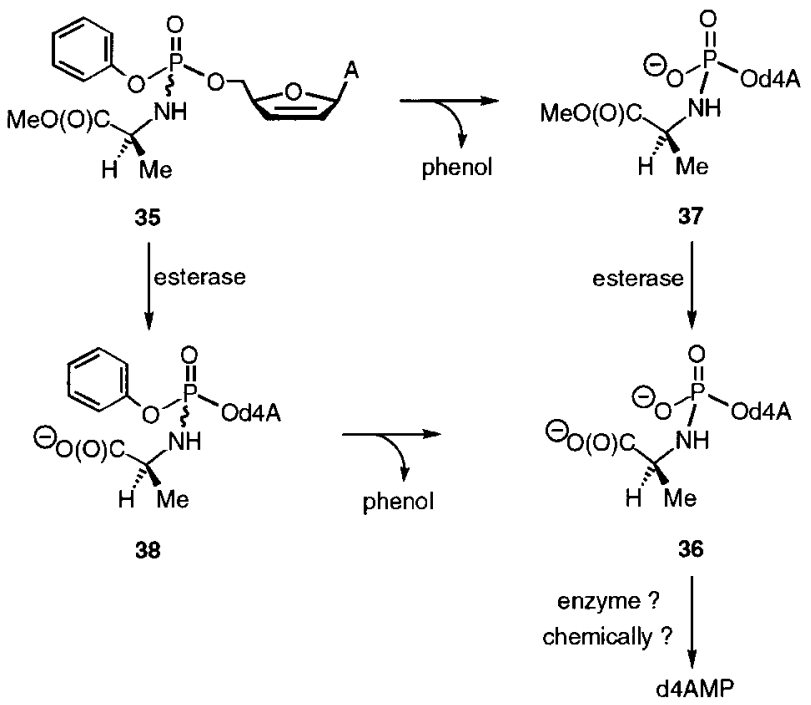

Figure 8. Proposed delivery mechanism of $2^{\prime}, 3^{\prime}$-dideoxy-2',3'-didehydroadenosine monophosphate (d4AMP) from the L-alanine-d4A phenylphosphoramidate 35

This new metabolite was not only observed in lymphoblastoid CEM cells but also in a variety of other cells although in varying amounts. Additionally, L. Naesens et al. have shown that the antiviral activity of the $\mathrm{d} 4 \mathrm{~T}$ phosphoramidate compounds was clearly related to the formation of the new metabolite: when different $\mathrm{d} 4 \mathrm{~T}$ prodrugs were incubated in crude CEM cell extracts, the L-alanine containing phosphoramidate resulted in the highest amounts of L-alaninyl d4TMP and showed the best antiviral activity, whereas the lowest amounts and no biological activity were detected for D-alanine, L- $\beta$-alanine, $\mathrm{L}$ leucine and L-valine ${ }^{(57)}$. Surprisingly, this concept is not successful for $\mathrm{AZT}^{(48)}$ and 3TC (lamivudine) ${ }^{(49)}$ for the inhibition of HIV-1 replication in CEM cells. The AZT phosphoramidate showed a 10-fold decrease in bioactivity as compared to the parent nucleoside against HIV-1 and HIV-2 in wild-type CEM/O cells and furthermore, this antiviral activity could not be retained against HIV-2 in CEM/TK ${ }^{-}$cells. The same was observed for the 3TC-containing derivatives which were also less active as the free nucleoside analogue 3TC against HIV-1 and HIV-2 replication already in the wild-type cell line.
J. Balzarini et al. showed that the corresponding ddA 6 and $\mathrm{d} 4 \mathrm{~A}$ derivatives (shown in Figure 8) markedly increased the antiviral potency of the parent nucleosides in different cell lines ${ }^{(50)}$. The most obvious interpretation of these data is the efficient delivery of the appropriate nucleotides ddAMP $\mathbf{8}$ and d4AMP, respectively, which leads to the ADA-bypass. It should be added that for the ddA and the $\mathrm{d} 4 \mathrm{~A}$ phosphoramidate derivatives an increase in the selectivity index compared to the free nucleosides was observed. Furthermore, both adenosine analogues were efficient as 3TC in inhibiting hepatitis-B virus replication in hepatocytes. As a consequence, these derivatives rank among the most potent HIV and HBV inhibitors reported so far in cell culture.

\section{Amino Acid Phosphoramidate Diesters}

Recently, C. Wagner et al. published an approach using phosphoramidates 39 bearing aromatic amino acids that are still negatively charged ${ }^{(58)}$. The approach has been applied to the nucleosides d4T $\mathbf{1}^{(58)}$, AZT $\mathbf{2}^{(59)}, 5$-FdU $\mathbf{3}^{(60)}$, and 3'-fluoro-3'deoxythymidine (FLT) ${ }^{(58)}$ (Figure 9). In few cases the reported phosphoramidates exhibited greater potency than the parent nucleosides in vitro. As amino acid L-tryptophan was found to be the best choice: in vitro, the L-tryptophan-AZT phosphoramidate demonstrated a 8-fold increase in antiviral activity compared to free AZT 2 against HIV-1 replication in peripheral blood mononuclear cells without toxicity ${ }^{(59)}$. Furthermore, cells treated with the active AZT diester contained 4-fold more phosphorylated AZT than those treated only with $\mathrm{AZT}^{(59)}$. Again, this high biological activity could not be transferred to the antitumoractive nucleoside 5-FdU 3. Evaluation of the corresponding Ltryptophan-5-FdU phosphoramidate demonstrated a pronounced decrease in antitumor activity of the prodrug compared to free 5-FdU in several cell lines. Although some of the activity was gained back by using permeabilized cells, even in these cells the activity was still lower than the activity of the parent nucleoside $\mathbf{3}$ in intact cells. However, incubation of cell-free extracts of CEM cells with radiolabelled Ltryptophan-5-FdU phosphoramidate resulted in the rapid production of 5-FdUMP and a lag in the generation of 5-FdU $3^{(60)}$. It should be added that this approach is the only reported case that successfully uses phosphodiesters as a prodrug concept. It has been shown that due to the remaining charge, the compounds are still considerably water soluble and furthermore, the compounds are indefinitely stable in human blood. The high stability was also observed in $20 \%$ calf serum after two-day incubation. Most probably, the phosphoramidates are cleaved by an enzymatic process. Interestingly, C. Wagner claimed that mechanistic studies attempting to characterize the activity of these compounds have revealed that the metabolism of phosphoramidates of nucleosides in proliferating tissue can proceed through direct $\mathrm{P}-\mathrm{N}$-bond cleavage by a so far unknown hydrolyzing enzyme ("phosphoramidase") ${ }^{(61)}$. Further work is in progress to identify the involved enzyme. Possibly this "phosphoramidase" is identical with the degrading enzyme of the

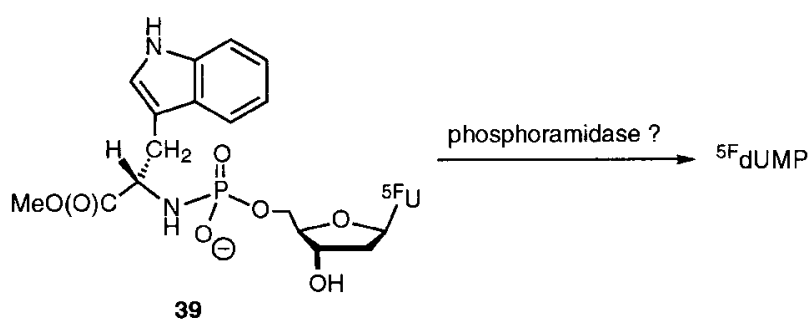

Figure 9. Proposed delivery mechanism of 5-fluoro-2'-deoxyuridine monophosphate (5-FdUMP) from charged 5-FdU phosphoramidate 39 
intermediate phosphoramidate $\mathbf{3 6}$ of $\mathrm{C}$. McGuigan discussed previously ${ }^{(46,56)}$.

\section{CycloSal-Nucleotides}

We have designed and synthesized a new and entirely different pronucleotide approach ${ }^{(62,63)}$ that can be cleaved by a selective chemical hydrolysis mechanism: the cyclosaligenyl nucleoside monophosphate approach (cycloSal-NMP). The concept was successfully introduced with the anti-HIV nucleosides ddT ${ }^{(64)}$, d4T $\mathbf{1}^{(65)}$ and ddA 6 (cycloSalddAMP 40; Figure 10) ${ }^{(66)}$. Although the general structure and the delivery mechanism is identical, the biological task of the compounds is different: While the $\mathrm{d} 4 \mathrm{~T}$ derivatives were designed to cause the TKbypass, the ddA analogues $\mathbf{4 0}$ were used for the ADA-bypass.

In contrast to all approaches mentioned previously, the delivery mechanism was designed to selectively release the nucleotide, e.g. ddAMP 8 and the masking group by controlled, chemically induced hydrolysis involving a successive, coupled cleavage of the phenyl- and the benzylester of the phosphotriester 40 (tandem mechanism). The coupling of the two ester hydrolysis steps is quite important because the chemical $^{(17)}$ and sometimes even the enzymatic hydrolysis ${ }^{(29)}$ of the intermediate phosphodiesters is extremely difficult (step d, Figure 10). Only the introduction of a phenyl-, a benzyl- and an alkyl phosphate ester allows us to discriminate chemically between the different phosphate ester bonds with the result of a controlled hydrolysis of a tripartate prodrug system ${ }^{(14)}$. The rationale of our new prodrug concept is based on the difference in stability of the phenyl- ${ }^{(67)}$ and the benzyl phosphate ester ${ }^{(68)}$. The phenyl ester bond should be the most labile one because the negative charge could be delocalized in the aromatic ring leading to the 2-hydroxybenzylphosphodiester 41 (step a, Figure 10). The alternative cleavage of the benzyl ester in $\mathbf{4 0}$, respectively, to yield the 2-hydroxymethylphenylphosphodiester $\mathbf{4 2}$ is unfavorable (step c, Figure 10), because the phosphate residue in the ortho-position of the benzyl ester stabilizes this bond. Hence, in the initial step, the phenyl ester is cleaved selectively with the consequence, that the orthosubstituent to the benzyl group switched from an acceptor (phosphate) to a donor group (hydroxyl). As a result, the remaining masking group is activated by this "Umpolung" of the 2-substituent. This induces the spontaneous cleavage of diester $\mathbf{4 1}$ to yield the nucleotide ddAMP 8 and the diols $\mathbf{4 3}$ (tandem reaction; step b, Figure 10). The main difference to the aforementioned chemically stable and enzymatically activated pronucleotide concepts is that our concept requires only one activation step

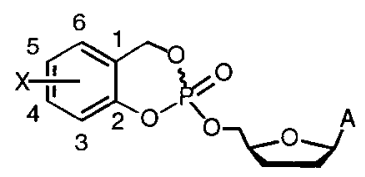

40

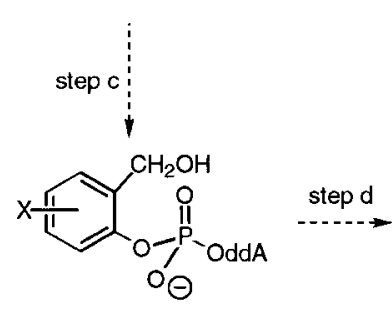

42
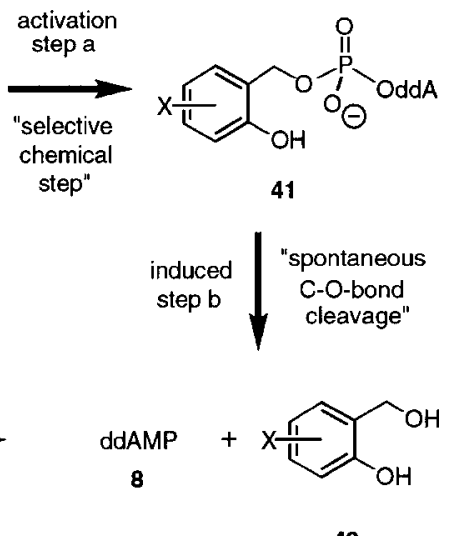

43
$\mathrm{X}=\mathrm{NO}_{2}, \mathrm{Cl}, \mathrm{H}, \mathrm{CH}_{3}, \mathrm{OCH}_{3}$

Figure 10. Selective delivery by a tandem reaction of 2',3'-dideoxyadenosine monophosphate (ddAMP 8) from lipophilic cycloSal-nucleotides $\mathbf{4 0}$ to deliver the nucleotide. The hydrolysis concept has already been verified by a study using multinuclear NMR spectroscopy $\left({ }^{1} \mathrm{H},{ }^{13} \mathrm{C},{ }^{31} \mathrm{P}\right.$ NMR) ${ }^{(65)}$ and mass spectrometry.

It should be added that in our concept neither the potentially toxic compounds formaldehyde or episulfide nor pivalinic acid are formed. However, as in the mentioned bis( $\mathrm{AB}$ ) approach, we may generate a 2'quinonemethide intermediate. But in contrast to the bis(AB) concept, we do not form this species in the close vicinity of an enzyme active site because no enzyme is required to activate the cycloSal compounds. So, the 2 -quinonemethide should be rapidly quenched by water to give the salicylalcohols 43. Furthermore, it should be stressed, that in contrast to almost all other discussed pro-nucleotide approaches we liberate only one masking group because the cycloSal group functions as a bidented masking group.

Chemical hydrolysis of the cycloSal-d4TMP or cycloSal-ddAMP derivatives confirmed the exclusive degradation to the nucleotides as well as the formation of the salicylalcohols $\mathbf{4 3}^{(65,66)}$. These experiments in different aqueous buffers and in RPMI-1640 culture medium with $10 \%$ heat-inactivated fetal calf serum showed the expected $\mathrm{pH}$ dependence of the nucleotide delivery typical for a chemical hydrolysis. Furthermore, a clear correlation of the electronic properties introduced by the salicylalcohol substituents and the hydrolysis half-lives of the phosphotriesters was observed ${ }^{(65,66)}$. No evidence for a degradation by enzymes present in RPMI-1640 medium with 10\% FCS has so far been observed but further hydrolysis studies in culture medium, in plasma and in cell extracts are in progress in our laboratory. The donorsubstituted cycloSal-NMPs, which exhibited half-lives of 7-35 hours, should be interesting candidates for biological evaluation. Moreover, the cycloSal-nucleotides showed a marked increase in lipophilicity (log $\mathrm{Pa}$ value in 1-octanol/water) with respect to the parent nucleosides which points to a potentially higher diffusion through the cellular membranes and through the blood-brain barrier. Despite of the higher lipophilicity, it should be emphasized, that cycloSal triesters are still reasonably water soluble.

The effectiveness of the cycloSal-nucleotides was demonstrated in in vitro antiviral assays. For cycloSal-d4TMPs, a correlation of the structure and the biological activity as in the hydrolysis studies has been found: The stronger the electron-donating activity of the substituent, the better the antiviral activity against HIV-1 and HIV-2 in CEM/O cells and the 3-, 5-methyl- as well as the 3,5-dimethyl-cycloSal-d4TMPs exhibited even higher antiviral potency $(0.09 \mu \mathrm{M})$ in the wild-type cell line as d4T $1(0.18 \mu \mathrm{M})$. Moreover, particularly striking is the complete retention of the biological activity in thymidine kinase-deficient CEM/ $\mathrm{TK}^{-}$cells for most of the compounds. Only the most labile 5-nitrocycloSal-d4TMP showed a complete loss in antiviral activity. These results confirm the highly selective intracellular delivery of d4TMP and prove the efficient TK-bypass. Additionally, the high biological activity of the donor-substituted cycloSal-d4TMP derivatives was also observed in MT-4 and Molt4/C8 cells ${ }^{(65)}$.

The cycloSal-concept has also been successfully applied for the prevention of the ADA deamination of ddA 6. The cycloSal-ddAMPs 40 exhibited very high antiviral activity in CEM/O-cells $(0.03 \mu \mathrm{M}$; up to a 100-fold increase as compared to ddA $6(3.17 \mu \mathrm{M}))^{(66)}$. Beside the high activity, a 15-fold increase in the selectivity index was found. Again, these results point to an efficient delivery of the nucleotide ddAMP 8. It should be added, that the intact cycloSal-ddAMPs $\mathbf{4 0}$ were completely resistant to enzymatic deamination by adenosine deaminase (ADA) or adenosine monophosphate deaminase (AMPDA), so that the biological activity is not caused by the delivery of ddIMP. It should be added, that, so far no correlation between lipophilicity and biological activity has been observed. 
In addition to the cycloSal phosphotriesters, the differently substituted salicylalcohols were also tested for their antiviral or toxic potency. Always $\mathrm{EC}_{50}$ values as well as $\mathrm{CC}_{50}$ values $>250 \mu \mathrm{M}$ were found. Apparently, the diols are neither responsible for the antiviral activity nor cause toxicity. Beside the dideoxynucleoside analogues d4T 1 and ddA 6, the cycloSal approach has also been applied to AZT $\mathbf{2}^{(69)}$. Surprisingly, the corresponding cycloSal-AZTMP derivatives were losing nearly all the antiviral activity in mutant thymidine kinasedeficient $\mathrm{CEM} / \mathrm{TK}^{-}$cells although the in vitro activity in the wild-type CEM cell line was identical to that of the parent nucleoside 2 Consequently, it seems that there is a special metabolic limitation that is acting against the retention of activity in the $\mathrm{TK}^{-}$cells. A comparable failure in biological activity was observed for various cycloSal-5FdUMP phosphotriesters ${ }^{(70)}$. In these cases, the antitumor activity of the phosphotriesters was even lower as compared to the nucleoside 5-FdU.

Summarizing, the cycloSal approach is the first example of a successful nucleotide delivery system that can be activated by non-enzymatic hydrolysis using a tandem reaction. As compared to the bis(SATE) approach $^{(34,36)}$ or the phosphoramidate approach ${ }^{(46)}$ the biological potency is comparable. This is essentially the case when our concept is compared side-by-side with the phosphoramidate approach. The advantages of the cycloSal concept is the easy synthetic excess and the reasonable solubility of the compounds in aqueous media as compared to the other methodologies. Moreover, the drug/masking group ratio in the cycloSal concept is $1: 1$, whereas in almost all nucleotide delivery systems that require enzyme activation the ratio is $1: 2$. Obviously, this 1:1-ratio is favorable in terms of potential toxicity effects. Additionally, we believe that a pro-nucleotide which can be cleaved by $\mathrm{pH}$-control should have advantages in in vivo applications because this approach is not directly dependent on different enzyme concentrations within a living system.

\section{Conclusion}

Summarizing the presented approaches, in the last few years the concepts for nucleotides delivery systems have been considerably improved for bioavailability or antiviral activity. All the approaches demonstrated convincingly the intracellular delivery of the antiviral active nucleotide. Although some approaches proved considerably antivirally active and superior to the parent nucleoside, there are still requirements with regard to toxicity aspects of the masking group, to solubility, to transport phenomena, to selective trigger activation mechanisms and to easier synthetic approaches that have to be addressed. However, the intrinsic high biological potential of some dideoxynucleotide analogues merit further work to the rational design of highly efficient pro-nucleotides for antiviral and antitumor application.

\section{Acknowledgements}

The author gratefully acknowledge the support by the Deutsche Forschungsgemeinschaft, the Fonds der Chemischen Industrie and the Adolf-Messer-Stiftung.

\section{References and Notes}

(1) (a) De Clercq, E. J. Med. Chem. 1986, 29, 1561-1569. (b) De Clercq, E. J. Med. Chem. 1995, 38, 2491-2517. (c) Périgaud, C.; Gosselin, G.; Imbach, J.-L. Nucleosides \& Nucleotides 1992, 11, 903-945.

(2) (a) Herdewijn, P.; Balzarini, J.; De Clercq, E. in: Advances in Antiviral Drug Design. (Ed. De Clercq, E.), 1993, Vol. 1, 233-318. (b) Herdewijn, P.; Balzarini, J.; De Clercq, E.; Pauwels, R.; Baba,
M.; Broder, S.; Vanderhaeghe, H. J. Med. Chem. 1987, 30, 12701278. (c) Mitsuya, H.; Broder, S. Proc. Natl. Acad. Sci., USA 1986, 83, 1911-1915.

(3) Furman, P.A.; Fyfe, J.A.; St. Clair, M.H.; Weinhold, K.; Rideout, J.L.; Freeman, G.A.; Lehrmann, S.N.; Bolognesi, D.P.; Broder, S. Proc. Natl. Acad. Sci., USA 1986, 83, 8333-8337.

(4) (a) Balzarini, J. Pharm. World Sci. 1994, 16, 113-126. (b) Hao, Z; Cooney, D.A.; Hartman, N.R.; Perno, C.-F.; Fridland, A.; DeVico, A.L.; Sarngadharan, M.G.; Broder, S.; Johns, D.G. Mol. Pharmacol. 1988, 34, 431-435.

(5) (a) Riddler, S.A.; Anderson, R.E.; Mellors, J.W. Antiviral Res. 1995, 27, 189-203. (b) Hitchcock, M.J.M. Antiviral Chem Chemother. 1991, 2, 125-132. (c) Ho, H.-T.; Hitchcock, M.J.M. Antimicrob. Agents Chemother. 1989, 33, 844-849. (d) Baba, M.; Pauwels, R.; Herdewijn, P.; De Clercq, E.; Desmyter, J.; Vandeputte, M. Biochem. Biophys. Res. Commun. 1987, 142, 128134. (e) Mansuri, M.M.; Starrett Jr, J.E.; Ghazzouli, I.; Hitchcock, M.J.M.; Sterzycki, R.Z.; Brankovan, V.; Lin, T.-S.; August, E.M.; Prusoff, W.H.; Sommadossi, J.-P.; Martin, J.C. J. Med. Chem. 1989, 32, 461-466. (f) Lin, T.-S.; Schinazi, R.F.; Prusoff, W.H. Biochem. Pharmacol. 1987, 36, 2713-2718. (g) Zhu, Z.; Ho, H.T.; Hitchcock, M.J.M.; Sommadossi, J.-P. Biochem. Pharmacol. 1990, 39, R15-R19.

(6) (a) Balzarini, J.; Herdewijn, P.; De Clercq, E. J. Biol. Chem. 1989, 264, 6127-6133. (b) Balzarini, J.; Kang, G.-J.; Dalal, M.; Herdewijn, P.; De Clercq, E.; Broder, S.; Johns, D.G. Mol. Pharmacol. 1987, 32, 162-167. (c) Sommadossi, J.-P. J. Infect. Dis. 1995, 171, S88-S92.

(7) Hao, Z.; Cooney, D.A.; Farquhar, D.; Perno, C.-F.; Zhang, K.; Masood, R.; Wilson, Y.; Hartman, N.R.; Balzarini, J.; Johns, D.G. Mol. Pharmacol. 1990, 37, 157-163.

(8) (a) Cooney, D.A.; Ahluwalia, G.; Mitsuya, H.; Fridland, A.; Johnson, M.A.; Hao, Z.; Dalal, M.; Balzarini, J.; Broder, S.; Johns, D.G. Biochem. Pharmacol. 1987, 36, 1765-1768. (b) Bloch, A.; Robins, M.J.; McCarthy, J.R., Jr. J. Med. Chem. 1967, 10, 908-912.

(9) Johnson, M.A.; Ahluwalia, G.; Connelly, M.C.; Cooney, D.A.; Broder, S.; Johns, D.G. J. Biol. Chem. 1988, 263, 15354-15357.

(10) Mitsuya, H.; Weinhold, K.J.; Furman, P.A.; St. Clair, M.H.; Nusinoff-Lehrman, S.; Gallo, R.C.; Bolognesi, D.; Barry, D.W.; Broder, S. Proc. Natl. Acad. Sci., USA 1985, 82, 7096-7100.

(11) (a) Cinatl Jr, J.; Gröschel, B.; Zehner, R.; Cinatl, J.; Périgaud, C.; Gosselin, G.; Imbach, J.-L.; Doerr, H.W. Antiviral Chem. \& Chemother. 1997, 8, 343-352. (b) Dianzani, F.; Antonelli, G.; Turriziani, O.; Riva, E.; Swimeoni, E.; Signoretti, C.; Strosselli, S.; Cianfriglia, M. AIDS Res. Human Retroviruses 1994, 10 , 1471-1478.

(12) A more extensive overview of older nucleoside and nucleotide prodrugs summarizing also part of the tripartate prodrug concepts can be found in: Jones, R.J.; Bischofberger, N. Antiviral Res. 1995, 27, 1-17 and cited literature. (b) Périgaud, C.; Giradet, J.-L.; Gosselin, G.; Imbach, J.-L. in: Advances in Antiviral Drug Design. (Ed. De Clercq, E.), 1996, Vol. 2, 147-172. (c) Gosselin, G.; Imbach, J.-L. Int. Antiviral News 1993, 1, 100-102.

(13) (a) Stella, V.J. J. Med. Chem. 1980, 23, 1275-1285. (b) Sinkula, A.A.; Yalkowsky, S.H. J. Pharm. Sci. 1980, 64, 181-210.

(14) Carl, P.L.; Chakravarty, P.K.; Katzenellenbogen, J.A. J. Med. Chem. 1981, 24, 479-480.

(15) Holmstedt, B. Pharmacol. Rev. 1959, 11, 569-618. 
(16) (a) Aldridge, W.; Davison, A. Biochem. J. 1952, 51, 62-70. (b) Ashini, Y.; Snyder, S.; Wilson, I. J. Med. Chem. 1973, 16, 446.

(17) It is well known in literature that phosphodiesters are extremely stable against chemical hydrolysis at physiological $\mathrm{pH}$ values: Bunton, C.A.; Mhala, M.M.; Oldham, K.G.; Vernon, C.A. J. Chem. Soc. 1960, 3293-3301. Even the "reactive" diphenylphosphate showed a half live of 180 years(!) at $\mathrm{pH} 7.0$ and $100^{\circ}$ C: Kirby, A.J.; Younas, M. J. Chem. Soc. (B) 1970, 510513 .

(18) (a) Westheimer, F.H. Acc. Chem. Res. 1968, 1, 70-78. (b) Buchwald, S.L. Pliura, D.H.; Knowles, J.R. J. Am. Chem. Soc. 1984, 106, 4916-4922.

(19) Srinivas, R.V.; Robbins, B.L.; Connelly, M.C.; Gong, Y.-F.; Bischofberger, N.; Fridland, A. Int. Antiviral News 1994, 2, 53-55.

(20) Farquhar, D.; Srivastava, D.N.; Kattesch, N.J.; Saunders, P.P. J. Pharm. Sci. 1983, 72, 324-325.

(21) Sastry, J.K.; Nehete, P.N.; Khan, S.; Nowak, B.J.; Plunkett, W.; Arlinghaus, R.B.; Farquhar, D. Mol. Pharmacol. 1992, 41, 441445 .

(22) Pompon, A.; Lefebvre, I.; Imbach, J.-L.; Khan, S.; Farquhar, D. Antiviral Chem. Chemother. 1994, 5, 91-98.

(23) Srinivas, R.V.; Robbins, B.L.; Connelly, M.C.; Gong, Y.-F.; Bischofberger, N.; Fridland, A. Antimicrob. Agents Chemother. 1993, 37, 2247-2250.

(24) (a) Farquhar, D.; Khan, S.; Srivastva, D.N.; Saunders, P.P. J. Med. Chem. 1994, 37, 3902- 3909. (b) Farquhar, D.; Chen, R.; Khan, S. J. Med. Chem. 1995, 38, 488-495.

(25) Jones, R.J.; Arimilli, M.N.; Lin, K.-Y.; Louie, M.S.; McGee, L.R.; Shaw, J.-P.; Burman, D.; Lee, M.; Kennedy, J.A.; Prisbe, E.J.; Bischofberger, N.; Lee, W.A.; Cundy, K.C. Abstract OP11; XII International Roundtable Nucleosides, Nucleotides and their biological Application, September 15-19, 1996, La Jolla, USA.

(26) (a) Arimilli, M.N.; Kim, C.U.; Dougherty, J.; Mulato, A.; Oliyai, R.; Shaw, J. P.; Cundy, K. C.; Bischofberger, N.; Antiviral Chem. \& Chemother. 1997, 8, 557-564. (b) Fridland, A.; Robbins, B.L.; Srinivas, R. V.; Arimilli, M.; Kim, C.; Bischofberger, N. Antiviral Res. 1997, 34, A49, 27.

(27) Naesens, L.; Bischofberger, N.; Arimilli, M.; Kim, C.; De Clercq, E. Antiviral Res. 1997, 34, A50, 28; Work presented at the 10th International Conference on Antiviral Research, April 6-11, 1997, Atlanta, Georgia, USA.

(28) (a) Périgaud, C.; Gosselin, G.; Imbach, J.-L. Curr. Topics in Med. Chem. 1997, 2, 15-29. (b) Gosselin, G.; Giradet, J.-L.; Périgaud, C.; Benzaria, S.; Lefebvre, I.; Schlienger, N.; Pompon, A.; Imbach, J.-L. Acta Biochim. Pol. 1996, 43, 195-208. (c) Puech, F.; Gosselin, G.; Lefebvre, I.; Pompon, A.; Aubertin, A.-M.; Kirn, A.; Imbach, J.-L. Antiviral Res. 1993, 22, 155-174. (d) Valette, G.; Pompon, A.; Girardet, J.-L.; Cappellacci, L.; Franchetti, P.; Grifantini, M.; La Colla, P.; Loi, A. G.; Périgaud, C.; Gosselin, G.; Imbach, J.-L. J. Med. Chem. 1996, 39, 1981-1990.

(29) Giradet, J.-L.; Gosselin, G.; Périgaud, C.; Balzarini, J.; De Clercq, E.; Imbach, J.-L. Nucleosides \& Nucleotides 1995, 14, 645-647.

(30) (a) Benzaria, S.; Pélicano, H.; Johnson, R.; Maury, G.; Imbach, J.L., Aubertin, A.-M.; Obert, G.; Gosselin, G. J. Med. Chem. 1996, 39, 4958-4965. (b) Benzaria, S.; Gosselin, G.; Pélicano, H.; Maury, G.; Aubertin, A.-M.; Obert, G.; Kirn, A.; Imbach, J.-L. Nucleosides \& Nucleotides 1995, 14, 563-565.
(31) Pugaeva, V.P.; Klochkeva, S.I.; Mashbits, F.D.; Eizengart, R.S. Gig. Tr. Prof. Zabol. 1969, 13, 47-48 (Chem. Abstract 72, 212).

(32) Luethy, J.; Von Daeniken, A.; Friedrich, U.; Manthey, B.; Zweifel, U.; Schlatter, C.; Benn, M.H. Mitt. Geb. Lebensmittelunters. Hyg. 1981, 72, 131-133 (Chem. Abstracts 95, 127093).

(33) Périgaud, C.; Girardet, J.-L.; Lefebvre, I.; Xie, M.-Y.; Aubertin, A.-M.; Kirn, A.; Gosselin, G.; Imbach, J.-L.; Sommadoussi, J.-P. Antiviral Chem. \& Chemother. 1996, 7, 338-345.

(34) (a) Lefebvre, I.; Périgaud, C.; Pompon, A.; Aubertin, A.-M.; Girardet, J.-L.; Kirn, A.; Gosselin, G.; Imbach. J.-L. J. Med. Chem. 1995, 38, 3941-3950. (b) Lefebvre, I.; Pompon, A.; Périgaud, C.; Girardet, J.-L.; Gosselin, G.; Aubertin, A.-M.; Kirn, A.; Imbach, J.-L. Nucleosides \& Nucleotides 1995, 14, 763-766.

(35) Girardet, J.-L.; Périgaud, C.; Aubertin, A.-M.; Gosselin, G.; Kirn, A.; Imbach, J.-L. Bioorg. Med. Chem. Lett. 1995, 5, 2981-2984.

(36) (a) Périgaud, C.; Aubertin, A.-M.; Benzaria, S.; Pelicano, H.; Girardet, J.-L.; Maury, G.; Gosselin, G.; Kirn, A.; Imbach, J.-L. Biochem. Pharmacol. 1994, 48, 11-14. (b) Périgaud, C.; Gosselin, G.; Benzaria, S.; Girardet, J.-L.; Maury, G.; Pélicano, H.; Aubertin, A.-M.; Kirn, A.; Imbach, J.-L. Nucleosides \& Nucleotides 1995, 14, 789-791.

(37) Schlienger, N.; Périgaud, C.; Gosselin, G.; Imbach, J.-L. Work presented at the 12th International Round Table Nucleosides, Nucleotides \& their biological Application, September 15-19, 1996, La Jolla, USA.

(38) Schlienger, N.; Périgaud, C.; Gosselin, G.; Lefebvre, I.; Pompon, A.; Aubertin, A.-M.; Kirn, A.; Imbach, J.-L. Work presented at the 12th International Round Table Nucleosides, Nucleotides \& their biological Application, September 15-19, 1996, La Jolla, USA.

(39) Routledge, A.; Walker, I.; Freeman, S.; Hay, A.; Mahmood, N. Nucleosides \& Nucleotides 1995, 14, 1545-1558.

(40) (a) Glazier, A.; Kwong, C.; Rose, J.; Buckheit, R. Antiviral Res. 1992, 17, (Suppl. 1), 66. (b) Glazier, A.; Buckheit, R.; Yanachkova, M.; Yanachkov, I.; Wright, G.E. Antiviral Res. 1994, 19, (Suppl. 1), 57.

(41) Thomson, W.; Nicholls, D.; Irwin, W.J.; Al-Mushadani, J.S.; Freeman, S.; Karpas, A.; Petrik, J. J. Chem. Soc., Perkin Trans. 1 1993, 1239-1244.

(42) (a) Thomson, W.; Nicholls, D.; Mitchell, A.G.; Corner, J.A.; Irwin, W.J.; Freeman, S. J. Chem. Soc., Perkin Trans. 1 1993, 2303-2308. (b) Mitchell, A.G.; Nicholls, D.; Irwin, W.J.; Freeman, S. J. Chem. Soc., Perkin Trans. 2 1992, 1145-1150. (c) Mitchell, A.G.; Thomson, W.; Nicholls, D.; Irwin, W.J.; Freeman, S. J. Chem. Soc., Perkin Trans 1, 1992, 2345-2353.

(43) Briggs, A.D.; Camplo, M.; Freeman, S.; Lundström, J.; Pring, B.G. Tetrahedron, 1996, 47, 14937-14950.

(44) Filar, L.; Winstein, S. Tetrahedron Lett. 1960, 25, 9-16.

(45) Glazier, A.; Yanachkova, M.; Yanachkov, I.; Wright, G.E.; Kern, E.R.; Sidwell, R.; Smee, D.; McKeough, M.; Spruance, S.L. Work presented at the 9th International Conference on Antiviral Research, May 19-24, 1996, in Urabandai, Fukushima, Japan.

(46) McGuigan, C.; Camarasa, M.-J.; Egberink, H.; Hartmann, K.; Karlsson, A.; Perno, C.F.; Balzarini, J. Int. Antiviral News 1997, 5, 19-21.

(47) McGuigan, C.; Cahard, D.; Sheeka, H.M.; De Clercq, E.; Balzarini, J. J. Med. Chem. 1996, 39, 1748-1753. 
(48) McGuigan, C.; Pathirana, R.N.; Balzarini, J.; De Clercq, E.; J. Med. Chem. 1993, 36, 1048-1052.

(49) Balzarini, J.; Wedgwood, O.M.; Kruining, J.; Pelemans, H.; Heijtink, R.; De Clercq, E.; McGuigan, C. Biochem. Biophys. Res. Commun. 1996, 225, 363-369.

(50) Balzarini, J.; Kruining, J.; Wedgwood, O.; Pannecouque, C.; Aquaro, S.; Perno, C.-F.; Naesens, L.; Witvrouw, M.; Heijtink, R.; De Clercq, E.; McGuigan, C. FEBS Letters 1997, 410, 324-328.

(51) McGuigan, C.; Wedgwood, O.M.; De Clercq, E.; Balzarini, J. Bioorg. Med. Chem. Lett. 1996, 6, 2359-2362.

(52) Balzarini, J.; Egberink, H.; Hartmann, K.; Karlsson, A.; Perno, C.F.; Cahard, D.; Naesens, L.; Thormar, E.; De Clercq, E.; McGuigan, C. Antiviral Res. 1996, 30, A18, 3; Work presented at the 9th International Conference on Antiviral Research, May 1924, 1996, in Urabandai, Fukushima, Japan.

(53) McGuigan, C.; Cahard, D.; Salgado, A.; De Clercq, E.; Balzarini, J. Antiviral Chem. Chemother. 1996, 7, 31-36.

(54) McGuigan, C.; Tsang, H.-W.; Cahard, D.; Turner, K.; Velazquez, S.; Salgado, A.; Bidois, L.; Naesens, L.; De Clercq, E.; Balzarini, J. Antiviral Res. 1997, 35, 195-204.

(55) McGuigan, C.; Salgado, A.; Yarnold, C.; Harries, T.Y.; De Clercq, E.; Balzarini, J. Antiviral Chem. Chemother. 1996, 7, 184188

(56) (a) Balzarini, J.; Karlsson, A.; Aquaro, S.; Perno, C.-F.; Cahard, D.; Naesens, L.; De Clercq, E.; McGuigan, C. Proc. Natl. Acad. Sci., USA 1996, 93, 7295-7299. (b) Balzarini, J.; Egberink, H.; Hartmann, K.; Cahard, D.; Vahlenkamp, T.; Thormar, E.; De Clercq, E.; McGuigan, C. Mol. Pharmacol. 1996, 50, 1207-1213.

(57) Naesens, L.; Cahard, D.; Salgado, A.; Bidois, L.; De Clercq, E.; McGuigan, C.; Balzarini, J. Antiviral Res. 1997, 34, A54, 40; Work presented at the 10th International Conference on Antiviral Research, April 6-11, 1997 in Atlanta, Georgia, USA.
(58) Abraham, T.W.; Wagner, C.R. Nucleosides \& Nucleotides 1994, 13, 1891-1903.

(59) Wagner, C.R.; McIntee, E.J.; Schinazi, R.F.; Abraham, T.W. Bioorg. Med. Chem. Letters 1995, 5, 1819-1824.

(60) Abraham, T.W.; Kalman, T.I.; McIntee, E.J.; Wagner, C.R. J. Med. Chem. 1996, 39, 4569-4575.

(61) McIntee, E.J.; Remmel, R.P.; Schinazi, R.F.; Abraham, T.W.; Wagner, C.R. J. Med. Chem. 1997, 40, 3323-3331 and Wagner, C.R. Antiviral Res. 1997, 34, A61, 68; work presented at the 10th International Conference on Antiviral Research, April 6-11, 1997 in Atlanta, Georgia, USA.

(62) Meier C. Angew. Chem. 1996, 108, 77-79; Angew. Chem. Int. Ed. Engl. 1996, 35, 70-72.

(63) Meier, C.; Knispel, T.; Lorey, M.; Balzarini, J. Int. Antiviral News 1997, $5,183-185$.

(64) Meier, C. University of Würzburg, unpublished results.

(65) (a) Meier, C.; Lorey, M.; De Clercq, E.; Balzarini, J. Bioorg. Med. Chem. Lett. 1997, 7, 99-104. (b) Meier, C.; Lorey, M.; De Clercq, E.; Balzarini, J. Nucleosides \& Nucleotides 1997, 16, in press. (c) Meier, C.; Lorey, M.; De Clercq, E.; Balzarini, J. J. Med. Chem. 1997, submitted.

(66) Meier, C.; Knispel, T.; De Clercq, E.; Balzarini, J. Bioorg. Med. Chem. Lett. 1997, 7, 1577-1582.

(67) Farrow, S.N.; Jones, A.S.; Kumar, A.; Walker, R.T.; Balzarini, J.; De Clercq, E. J. Med. Chem. 1990, 33, 1400-1406.

(68) Meier, C.; Habel, L.W.; Balzarini, J.; De Clercq, E. Liebigs Annalen der Chemie 1995, 2203-2208.

(69) (a) Meier, C.; De Clercq, E.; Balzarini, J. Liebig Annalen der Chemie 1997, submitted. (b) Meier, C.; De Clercq, E.; Balzarini, J. Nucleosides \& Nucleotides 1997, 16, 793-796.

(70) Lorey, M.; Meier, C.; De Clercq, E.; Balzarini, J. Nucleosides \& Nucleotides 1997, 16, 789-792. 